\title{
Un juego de palabras e insultos: el vóleibol como una práctica cotidiana queer en el Perú*
}

Justin Pérez

Traducción al castellano por Eduardo Romero. Originalmente publicado como «Word Play, Ritual Insult, and Volleyball in Peru» en la revista Journal of Homosexuality, 58(6-7), 834-847. Recuperado de https://tandfonline.com/

** Bachiller en Antropología por la Universidad de Notre Dame; y doctor y magíster en Antropología por la Universidad de California, Irvine. Actualmente es profesor asistente del Departamento de Estudios Latinos y Latinoamericanos en la Universidad de California, Santa Cruz. Correo electrónico: jdaperez@ucsc.edu

Fecha de recepción: 21/04/2020. Fecha de aceptación: 15/07/2020. 


\title{
Un juego de palabras e insultos: el vóleibol como una práctica cotidiana queer en el Perú
}

\section{RESUMEN}

El vóley es una actividad sumamente visible entre muchas personas gais y trans de los sectores urbanopopulares. A través de un trabajo de campo etnográfico realizado durante los años 2009 y 2010 con comunidades gais y trans en dos barrios ubicados en Lima Norte y en el Callao, en este artículo se describen las prácticas sociolingüísticas y corporales que emergieron dentro del contexto del vóley callejero y se demuestra cómo el deporte ilumina las intersecciones de la identidad, el lenguaje, el género y la sexualidad. El rol del vóley es profundamente comunal y social —yendo más allá de los saques, las defensas y el puntaje- - Específicamente, es por medio de las prácticas del insulto y la cultivación de una técnica particular como los interlocutores del estudio desafiaron los reglamentos del vóleibol formal e interrumpieron las normas de la vía pública. A través de la transformación cotidiana de la calle en una cancha de vóley, los participantes produjeron un espacio visible y un marco social para desarrollar y hacer legible una estética deportiva queer.

Palabras clave: Vóleibol, queer, género, insulto, espacio, Perú.

\section{A Game of Words and Insults: Volleyball as an Everyday Queer Practice in Peru}

\begin{abstract}
Volleyball is an especially visible activity among many gay and transgender people in popular, urban neighborhoods. Through ethnographic fieldwork carried out in 2009-2010 among gay and transgender communities in two neighborhoods, one located in the north of Lima and the other in Callao, this article describes the socio-linguistic and embodied practices that emerged during the context of street volleyball, demonstrating how sport illuminates the intersections of identity, language, gender, and sexuality. The role of volleyball is profoundly communal and social—going beyond serves, passes, and scoring. Specifically, study participants challenged the rules of formal volleyball and interrupted the norms of public space through shared practices of insulting and the cultivation of a particular volleyball technique. Through this everyday transformation of the street into a volleyball court, participants produced a visible space and social frame to develop and make legible a queer sporting aesthetic.
\end{abstract}

Keywords: Volleyball, Queer, Gender, Insult, Space, Peru. 


\section{INTRODUCCIÓN}

Este artículo es un esfuerzo por generar una aproximación etnográfica a una tensión central en los estudios queer contemporáneos en América Latina, a saber, ¿cómo y por qué la academia debería recurrir a la teoría queer — un aparato teórico surgido de las configuraciones particulares de género y sexualidad del contexto sociocultural norteamericano- para articular y responder a preguntas sobre configuraciones específicamente latinoamericanas? Esta tensión ha sido particularmente productiva en el campo de los estudios queer latinoamericanos, incluso cuando este campo ha emergido en el contexto peruano dentro de situaciones por lo general inesperadas y en los márgenes de las instituciones académicas formales (Cornejo Salinas, Martínez y Vidal-Ortiz, 2018). El deporte, y en particular el vóley, ofrece un marco social visible para examinar cómo estas tensiones se desarrollan en las vidas cotidianas entre algunas comunidades gais peruanas ${ }^{1}$.

El fútbol, tal como ha sido bien demostrado, ofrece un campo de estudio que puede producir un entendimiento profundo sobre dinámicas de clase, género y raza que atraviesan a la sociedad peruana. No hay duda de que el vóley es una actividad igual de amada por muchos peruanos. El vóley callejero, en específico, es un género de deporte que en Lima y Callao es particularmente apreciado entre hombres gay. Principalmente asociado a los sectores populares, el vóley callejero es practicado por hombres gay y, por lo general, los partidos que realizan atraen a numerosos espectadores que miran y alientan a los equipos. Los motivos de los asistentes para acercarse al juego varían. Algunos vienen a alentar a sus amigos y vecinos, otros lo hacen para entretenerse con los juegos de palabras y los insultos que los participantes usualmente se aplican entre sí; otros van a encontrar parejas sexuales potenciales, y otros lo hacen porque no hay nada más que pase ese día en su barrio.

En tanto actividad lúdica y dinámica, el vóley ofrece un punto de vista ventajoso para intervenir en las conceptualizaciones tradicionales sobre las culturas

\footnotetext{
1 Una breve nota con respecto a la nomenclatura: los peruanos tienen un rico y rápidamente cambiante vocabulario para hablar sobre subjetividades sexuales normativas y no normativas. Un vocabulario, además, que solo es explorado muy parcialmente por este artículo. El término gay solo se aproxima muy limitadamente al complejo vocabulario que los peruanos usan para identificar y comprender la vida sexual normativa y no normativa. La investigación original para este artículo, realizada entre 2009 y 2010 en Lima y Callao, estaba circunscrita en ese momento a interlocutores que se identificaban como gais. Debido a esto, si bien el término gay es limitado, es el que era usado para referirse a los sujetos de estudio. Aunque el término queer puede tener muchos usos, en esta versión revisada del artículo he decidido usar dicho término para referirme ya sea a una literatura o a un grupo de prácticas sociales. Si este estudio se realizara el día de hoy, se aproximaría con mayor sofisticación a estas distinciones terminológicas y atendería a las distinciones entre subjetividades gay, travesti y transgénero en las culturas sexuales del Perú costero y a las prácticas sociolingüísticas denominadas «húngaro». Ver Alcalde (2018), Cornejo (2019) y Vásquez del Águila (2013).
} 
homosexuales latinoamericanas que emergen de la literatura científica social. Históricamente, las diferencias entre los sistemas de sexualidad panlatinoamericanos y aquellos de Norteamérica/Europa han sido teorizados como diferencias entre metas sexuales [sexual aim] y elecciones de objeto sexual [sexual object choice]. En la lógica de la meta sexual, esta literatura argumenta y organiza el sistema de sexualidad panlatinoamericano, mientras que la elección del objeto sexual organiza los sistemas europeos y norteamericanos. En un sistema formado por la meta sexual, la homosexualidad se determinaba por el rol que uno cumple en el acto sexual. Un individuo que toma el rol de penetrador, el activo, no es estigmatizado con la etiqueta de homosexual. Por otro lado, el individuo penetrado, el pasivo, sí es considerado gay. Estas dos lógicas han sido retratadas históricamente como rígidas y antitéticas. Más recientemente, la globalización y el activismo relacionado con el VIH/sida han cuestionado la rigidez que define este aparato conceptual (Fuller, 2001; Peńa, 2004).

Por otro lado, el impulso por desenmascarar secretos ocultos, sórdidos y escandalosos ha motivado por mucho tiempo la atención académica hacia las cartografías de la homosexualidad. El controversial estudio de Humphrey que consistía en ir de ligue en baños públicos es quizás paradigmático de una fascinación académica sobre aquello que ocurre dentro de cuatro paredes y con las consecuencias éticas de tal fascinación. De igual modo, la epidemia de sida alentó a la academia sociocultural a dirigir su atención a los aspectos secretos y privados de la sexualidad gay: saber más sobre la sexualidad era fundamental para prevenir ciertas formas de transmisión del VIH. En el caso del Perú, debido a la concentración del VIH/sida entre las poblaciones de los así llamados HSH (hombres que tienen sexo con hombres), el análisis científico social del ambiente ha tendido a centrarse, por buenas razones, en espacios «riesgosos» de interacción social y sexual, tales como cuartos oscuros, saunas, discos, y deportes públicos de ligue. En una entrevista realizada por el periodista Lucien Chauvin (2005) al activista Enrique Bossio, este explicaba que «la homosexualidad en el Perú, como he dicho, todavía es tabú, y muchos hombres gais continúan viviendo su homosexualidad donde nadie puede verla» (p. 504). Sin embargo, los partidos cotidianos de vóley jugados en los parques y calles de Lima y Callao eran un nodo esencial de la socialidad gay. El vóley callejero es una performance pública y accesible, protagonizada por hombres gay que a menudo son reconocidos como tales por muchos de los que vienen a mirarlos. Una teorización de la socialidad gay que se centra en el encubrimiento y en lo oculto limita el entendimiento de cómo los gais peruanos cultivan sus identidades sexuales, sociales y de género a través de una práctica atlética. Por medio de la transformación física de un espacio urbano heterosexual y dominante, los jugadores de vóley son capaces de crear un marco de referencia queer en el cual técnicas particulares de vóley y de juegos de palabras sugieren o, más bien indexan, lo queer. 
Una noche calurosa de enero, acompañé a Tyra — quien se identifica como gay pero era coloquialmente llamado por este nombre- a un relámpago de vóley, un minitorneo de cuatro equipos que representaban a distintos barrios. Tyra y yo llegamos al parque alrededor de las 9:30 p.m., cuando ya estaba totalmente oscuro. La cancha estaba levemente iluminada por los faroles de la calle, y me quedé sorprendido por cuán bien los jugadores podían pasar y golpear la pelota en medio de tal oscuridad. La cancha de vóley estaba completamente rodeada por una multitud de animados espectadores: alrededor de sesenta, incluyendo niños. De repente, escuché gritos ruidosos y un vidrio que se rompía. Un grupo de hombres jóvenes vino corriendo por la esquina de la calle, algunos sin camisas y otros con bandanas amarradas sobre sus bocas. Al mismo tiempo, otro grupo que parecía estar conformado por adolescentes se aproximó corriendo por la otra esquina, tirando piedras y botellas de vidrio hacia la pandilla rival. En ese momento tuvo lugar una pelea entre los dos grupos, literalmente a unos metros de donde transcurría el juego de vóley. Los espectadores quedaron atónitos y se movieron al otro lado de la cancha, tomando distancia de la violencia, pero los jugadores continuaron su juego: no pararon ni siquiera a ver lo que estaba ocurriendo. Aunque esto me dejó sobresaltado, el hecho de encontrarme rodeado por otros espectadores me permitió mantener la calma. Luego de varios minutos, sirenas policiales comenzaron a sonar y las pandillas se dispersaron en la oscuridad del vecindario aledaño.

Este incidente me parece un reminiscente de la pelea de gallos balinesa de la que Geertz (1973) protagonizó un famoso escape. Como las peleas de gallos estaban prohibidas por las autoridades indonesias, cuando las autoridades se aproximaron todos huyeron para evitar ser capturados. El vóley callejero aparecía en contextos como este totalmente inserto en la vida pública cotidiana de los sectores populares de Lima. Entre el caos y el desorden de las peleas de pandillas y los vidrios rotos, el juego continuó sin complicaciones. En tanto minorías sexuales, los jugadores de vóley experimentaban marginalización y estigma, pero, como este hecho me demostró, la actividad del vóley callejero estaba central e íntimamente entretejida con la vida social del Perú urbano. De forma similar a la pelea de gallos de Geertz —un ritual a través del cual los balineses expresaban sus valores—, el vóley callejero emergía como una arena importante a través de la cual distintos sentidos culturales eran configurados y performados.

\section{TRANSFormaciones EFÍMERAS Del ESPaCio PÚBlico}

Transformar temporalmente el paisaje urbano en una cancha de vóley no era una tarea fácil, y los jugadores y espectadores peleaban constantemente para afirmar su reclamo por un espacio que no estaba originalmente diseńado para su uso particular. 
Si bien el juego era un concurso para los jugadores, una competencia de unos contra otros para ganar el dinero que era juntado para apostar, este también era, en otro sentido, un concurso por la territorialización. En otras palabras, el vóley callejero era una disputa por la legitimización de un uso particular del espacio frente a los usos de otros usuarios e, incluso, contra el espacio urbano en sí mismo. A veces, los jugadores y espectadores eran exitosos en esta transformación y sus juegos se desarrollaban sin cuestionamientos ni desafíos de otros usuarios durante el curso de toda la tarde o noche. La mayor parte del tiempo, sin embargo, el juego era interrumpido por otros usuarios. Por ejemplo, si un anciano o anciana caminaba por la cancha, el juego se interrumpía para que la pelota no chocara con el o la transeúnte. Para que un carro o bus pudiera pasar, el juego también debía ser interrumpido con el fin de que la red fuera alzada y el vehículo pudiera pasar por debajo de ella. Sin embargo, cuando muchos espectadores rodeaban la cancha, un carro que quisiera cruzar la pista no podía pasar y era forzado a retroceder por el mismo camino y encontrar otra ruta, lo cual transformaba al partido en una invasión exitosa de la calle.

Una cancha de vóley tenia que ser construida con y en la propia calle donde el partido se llevaría a cabo. Y este proceso tenía consecuencias significativas para una variedad de elementos integrales al juego. Así, el tiempo de duración que tendría el partido, la técnica de juego a emplear y el rol activo del espacio urbano en el desarrollo de las acciones convertían al vóley callejero en un juego casi diferente del vóley formal. Con el fin de crear el espacio de juego, los jugadores tenían que modificar temporalmente el paisaje urbano. Este proceso podía causar un cambio permanente en el espacio. Por ejemplo, una pelota golpeada fuertemente podía romper el vidrio de una ventana. Las fachadas de los edificios tenían marcas de cuando una pelota sucia impactaba en ellas. En algunos lugares, las líneas de la cancha estaban permanentemente pintadas en la calle. Sin embargo, el medio ambiente construido no era solo manipulado por los jugadores, puesto que también se constituía en una fuerza activa con la que los jugadores y espectadores se encontraban en constante negociación. Objetos comunes a este paisaje urbano no solo servían para demarcar las fronteras del juego, sino que también jugaban un rol activo durante el juego mismo. De este modo, la red era estratégicamente colgada atravesando la calle, atada a postes de luz o a edificios.

Aunque las fronteras de la cancha eran delineadas con tiza o pintadas en la calle, el medio ambiente construido también enmarcaba el juego. Por ejemplo, aunque la vereda servía como línea para la cancha, su presencia también afectaba el juego en tanto los jugadores estaban obligados a maniobrar su paso por la vereda cuando corrían por la pelota. Las líneas eléctricas colgaban sobre la cancha de vóley. Durante el juego, estas interrumpían y reorientaban la trayectoria de la pelota, que podía accidentalmente quedarse atascada en los techos o al otro lado de la pared. Los juga- 
dores aprendían cómo alterar los ángulos de sus pases y ataques con el fin de dirigir las pelotas lejos de un techo o un tendido eléctrico de una forma que no tendrían que hacer si estuviesen jugando en un espacio dedicado al deporte, como un gimnasio. Cuando el medio ambiente construido consumía la pelota, el flujo del juego era interrumpido para que alguien pudiera recuperarla, o cuando esta era irrecuperable, el partido acababa abruptamente.

Este proceso de adaptarse y maniobrar a través del espacio urbano comparte características con lo que Halberstam (2005) ha denominado espacio queer. Para reclamar su uso del espacio, al menos por la tarde, las personas que observé jugando vóley callejero recurrían a prácticas cotidianas que les permitían hacer sus vidas vivibles en tanto transgresores marginalizados de las normas sexuales y de género de la sociedad. Esto implicaba una reflexión y la búsqueda de una intersección con procesos relacionados a las estrategias de ligue. El ligue es la práctica de localizar potenciales parejas sexuales en parques, calles y plazas, y requiere prácticas de transformación particulares abocadas a «transformar el espacio por lo demás hostil del mundo heterosexual dominante en un campo de posibilidades eróticas» (Parker 1999, p. 56). Los jugadores invadían la calle y la transformaban en un espacio no solo adecuado para su juego de vóley: también hacían de un espacio normalmente desatendido un punto focal de la mirada del barrio. Esto resulta en un nivel adicional de juego: un metajuego de deseo. Tiene sentido que la búsqueda por compañeros sexuales, siempre lúdica, emerja como un elemento adicional dentro del vóley callejero. En tanto compañeros sexuales potenciales poblaban la heterogénea audiencia de espectadores de los partidos, los jugadores alteraban su estilo de juego con el fin de entrar en un juego de seducción dentro del desarrollo del vóley. Al doblar hacia arriba las mangas de sus camisas y shorts, y lanzar ostensibles miradas y guiños, los jugadores participaban en este juego de deseo. Esta dimensión de deseo es ciertamente familiar al juego de vóley. Sin embargo, también es tan solo una capa de sentido que está «atada a articulaciones de identidad» (Bucholtz y Hall, 2004, p. 498). Si el juego entre los atletas era el primer —y quizás el más obvio — nivel de juego en el contexto del vóley callejero gay, podemos identificar, además, un segundo nivel de juego desarrollado con el espacio urbano en sí mismo, y un tercer nivel que implicaba un tácito juego sexual que involucraba además a los propios espectadores. Un cuarto nivel, y quizás aquel que posee mayor significado cultural, era el espacio lúdico de los juegos de lenguaje y de las prácticas encarnadas de los participantes.

\section{El JUEgo de palabras}

Un estilo lingüístico emergía durante el desarrollo de los juegos de vóley callejero. Este estaba visiblemente marcado por el uso de insultos entre los jugadores. El uso 
juguetón de insultos reflejaba la naturaleza lúdica del vóley. Primero, durante el juego, los jugadores usualmente se referían entre ellos por sus apodos, por lo general de género femenino, y hablaban los unos de los otros usando el pronombre femenino. Por ejemplo, como observador participante de los partidos de vóley, era llamado la gringa, pero mientras participaba del juego, era referido en conversaciones como la Justina. Sin embargo, durante las entrevistas que realicé o en otros contextos fuera de la cancha de vóley, los mismos informantes se referían a mí como el gringo.

Tyra, interlocutora citada previamente en el artículo, utilizaba su nombre propio oficial fuera del contexto del vóley. Usando una camisa con el nombre Tyra escrito en la espalda, posiblemente fruto de un torneo de vóley previo, los jugadores individuales reiteraban la concordancia gramatical de género con su estilo de juego y con la selección de su vestimenta. Incluso espectadores de los partidos insistían en esta concordancia de género cuando hablaban sobre el juego de vóley. Por ejemplo, cuando estaba desarrollando una entrevista no estructurada con un espectador durante un juego, la persona en cuestión interrumpió nuestra conversación y gritó: «Tyra, esa bola cayó dentro, no seas picona».

Esta expresión no tenía ninguna conexión con lo que habíamos estado discutiendo, y era una reacción a lo que había tenido lugar en el juego. Durante el desarrollo de las acciones, Tyra estaba en la posición de defender un mate del equipo contrario por arriba. Como parte de su estrategia, Tyra dejó la bola pasar y entonces dijo que la bola había golpeado el piso fuera de la cancha, de tal forma que el punto correspondiese a su equipo. El equipo contrario creyó que la bola había golpeado en el piso dentro de la cancha, y se opuso a lo dicho por Tyra. Notando la conmoción, el espectador dijo que la bola había caído dentro de la cancha y que Tyra no debía ser picona y decir que había caído afuera. El espectador hizo así uso del femenino gramatical al aplicar la etiqueta de picón a Tyra, llamándola picona (femenino gramatical) y no picón (gramatical femenino). Dado que Tyra usaba dicho nombre para jugar vóley, hablar sobre ella requería gramaticalmente una concordancia de género. Hubiera sonado extraño si el espectador hubiera dicho «no seas picón» en este contexto.

Pero fuera del espacio de la cancha de vóley, el mismo espectador hablaría de Tyra usando su nombre masculino, y le aplicaría por consiguiente el masculino gramatical. El uso del gramatical femenino era lúdico y estaba coordinado con las prácticas del juego mismo. Al lanzar su comentario, el participante se insertaba alegremente en el juego, en lugar de permanecer como un espectador pasivo. La actividad del vóley enmarcaba la vida social y el espacio público de un modo tal que las formas particulares de hablar y de entender las relaciones sociales rearticulaban las subjetividades de los participantes.

El insulto era otro aspecto importante del vóley callejero. Dominar el insulto era necesario no solo para comunicarse con otros jugadores, sino para jugar el juego 
en general. Los insultos eran complejos y servían para varios propósitos. Primero, eran indicadores claros de las relaciones de broma que cultivaban mutuamente los jugadores. El entendimiento de la broma avanzado por Radcliffe-Brown se basa en «una relación entre dos personas donde, por costumbre, es permitido, y algunas veces incluso demandado, que uno haga bromas sobre el otro y que el otro a su vez no se ofenda» (p. 172). Mientras Radcliffe-Brown está interesado aquí en cómo las relaciones de broma resolvían las tensiones sociales características de relaciones con elementos de disyunción y conjunción, este estilo particular de establecer relaciones de broma era efímero y existía durante el juego de vóley. Sin embargo, las bromas operaban como una forma de evadir potenciales conflictos, pero de una forma diferente de la que Radcliffe-Brown describió. Durante las entrevistas que realicé con algunos de los espectadores de los partidos, la principal razón que documenté cuando pregunté sobre las razones para venir a los juegos de vóley, era poder escuchar los insultos que los jugadores se lanzaban los unos a los otros. Del mismo modo que Murray (1979) argumentaba que en algunas situaciones el insulto gay era una forma de performance puesta en escena para el beneficio de la audiencia, la performance verbal desarrollada en la cancha de vóley era uno de los elementos más atractivos del juego para los asistentes. Los jugadores, a su vez, sabían que su práctica, a los ojos de la comunidad, oscilaba entre ser aceptada y ser estigmatizada, o entre ser escandalosa y ser cómica. Un jugador entonces debía, por demanda de sus pares, evitar sentirse ofendido por un eventual insulto: más bien debía devolver el insulto, dado que esto entretendría al público. El insulto ayudaba así a resolver esta tensión, al proveer de entretenimiento a los espectadores. De este modo, los insultos también marcaban la membresía al grupo y alentaban la cohesión de los participantes.

A través del insulto, los jugadores demostraban su adquisición tanto de una competencia atlética como de una "competencia comunicativa» (Hymes, 1972). Para ganar el respeto de la cancha, un jugador no debe solo dominar el léxico gay, sino que debe suplementar esta competencia comunicativa con su capacidad para jugar vóley. Para desarrollar una performance disfrutable y positiva de vóley para los espectadores, los jugadores de vóley combinaban diestramente su capacidad de juego verbal con su igualmente diestra capacidad de jugar vóley. La combinación de juego físico y juego verbal proveía a los jugadores de la oportunidad de demostrar sus competencias. El contexto del vóley ofrecía, así, una combinación diversa de posibles formas en que los insultos podían ser intercambiados. La respuesta a un insulto podía ser verbal, normalmente jugando con las palabras del insulto original, y por lo general se focalizaba en la destreza sexual de un jugador.

A: Asquerosa, ármame.

B: Ni tu marido te la arma. 
En este ejemplo, A le pregunta a B que coloque la bola de tal manera que él pueda atacar. Sin embargo, A insulta a B llamándolo «asquerosa». En respuesta al insulto, $\mathrm{B}$, el armador, quien prefiere pasar la bola para otros jugadores, responde a A diciéndole que «ni tu marido te la arma». El humor resulta en este caso del hecho de que «armar» cambia de connotación en la segunda locución, de ser una palabra neutral en el vóley que significa colocar la bola, a ser un insulto de naturaleza sexual. B no le colocará la bola a A porque ni siquiera el marido de A tendría relaciones sexuales con él. Más frecuentes aún, sin embargo, son los insultos que resaltan la competencia lingüística y deportiva del jugador en cuestión, que son señaladas como superiores a las del oponente. Esta correlación es evidente en el siguiente ejemplo, el cual recogí luego de que un juego parara debido a una violación de la línea de juego.

\section{A: ¡Invasión!}

B: Invasión donde tú vives.

A acusa a $\mathrm{B}$ de cometer una violación a las reglas debido a que su pie cruzó la línea debajo de la red. B inmediatamente responde diciendo que A vive en una «invasión». B niega entonces la violación al reglamento sugiriendo que la invasión no es lo que él cometió sino donde A vive. De nuevo, el humor resulta de la habilidad de cambiar la connotación de un término neutral del vóley. Como podemos ver, los temas de los insultos son extraídos de referencias culturales queer compartidas. De este modo, los insultos pueden basarse en la supuesta inhabilidad de un jugador de estimular a un hombre, su apariencia física o su avanzada edad. Otro grupo de insultos emerge también de la cultura peruana en términos más amplios e implica características culturalmente establecidas como negativas, tales como la ascendencia andina. Así, tal como los hijras de India asumen control de un campo lingüístico a través del insulto con el fin de "cuestionar las cartografías dominantes del género y la sexualidad» (Hall, 1997, p. 452), los jugadores establecían en el contexto del vóley un control sobre el campo lingüístico a través de la abundancia de insultos. Al transformar el espacio físico y verbal, los jugadores de vóley generaban dentro del espacio de la cancha una reconfiguración temporal de las relaciones dentro de la comunidad.

\section{Performance encarnada}

El cuerpo mismo se convertía en el espacio del vóley callejero en un mecanismo de expresión fundamental. El juego permitía a los participantes la oportunidad de cuestionar normas dominantes del deporte. La mayoría de los jugadores estaban familiarizados con la forma y técnica del vóley estándar y, dependiendo del contexto 
de un juego de vóley particular, podían jugar usando la técnica formal. Incluso algunos jugadores de vóley profesional podían jugar en partidos de vóley callejero. Uno de los interlocutores de mi estudio era también un jugador profesional dentro de la liga profesional de vóley del Perú. Así como él podía alternar su registro discursivo dependiendo del contexto del juego - es decir, de si estaba jugando en el estadio o en la calle-, también podía ejecutar y maniobrar el juego entre dos técnicas de vóley distintas.

Cuando él jugaba en la liga profesional, lo hacía en arreglo a las técnicas formales del vóley. Sin embargo, en el contexto de la calle, alteraba esta técnica introduciendo en su estilo de vóley una estética queer. Es importante notar que, si bien no todos los jugadores tenían un entrenamiento formal extensivo, el vóley profesional era televisado y uno de los temas de conversación más discutidos durante y luego de los partidos de vóley callejero era el vóley profesional y la selección nacional. Otros jugadores también mencionaron haber participado en talleres de entrenamiento y tenían un dominio práctico de la técnica formal del vóley. Aquellos que no poseían este tipo de entrenamiento constantemente recibían retroalimentación y guía de aquellos que sí lo tenían, de modo que todos los participantes estaban conscientes y mostraban competencia en la técnica formal.

La forma estándar de la defensa en el vóley típicamente implica un mínimo movimiento de la parte superior del cuerpo. Asimismo, una buena posición de recepción implica agacharse bien y con las rodillas dobladas. La recepción y pase al armador normalmente implicaría el menor movimiento posible en los brazos, y el contacto normalmente se realiza con los antebrazos. El movimiento hacia la bola por el defensor es, asimismo, realizado enteramente con los pies, y los brazos eran más bien dejados en una posición relativamente fija. La bola sería dirigida y pasada al armador a través de la posición del cuerpo. Una defensa típica en un partido de vóley callejero se desviaba notoriamente de esta descripción. Los brazos eran el foco para la defensa y se movían frecuentemente para contactar la bola. Para pasar la bola, el jugador doblaba la cintura, en lugar de las rodillas. Con sus pies en una posición casi estacional, el jugador usaba sus brazos para localizar la bola y poder hacer un pase. El contacto era realizado al sacudir la muńeca con el fin de orientar la bola y pasarla al armador, minimizando así el movimiento de la parte inferior del cuerpo. El objetivo era demostrar poco esfuerzo a la hora de dar un pase, lo que permitía al jugador remarcar su superioridad y justificar el lanzamiento de un insulto a su oponente. Luego de que la bola era pasada, el defensor tenía un repertorio de otros usos del cuerpo a su disposición. Por ejemplo, si la bola terminaba en un mate, el jugador podía lanzar un beso al atacante, o podía hacer piruetas alrededor de un círculo luego del contacto con la pelota. La performance defensiva buscaba mostrar un mínimo esfuerzo y que el tiro lanzado luciera suave y fácil de defender. Aunque 
en realidad una importante cantidad de esfuerzo era necesaria para pasar efectivamente la bola desde esta posición, la performance tenía por objetivo lucir delicada y fluida. En consecuencia, la desviación de la forma estándar del vóley no era solo consciente, sino también eficaz. Al contestar la técnica formal, los jugadores usaban su cuerpo como medio para desarrollar un espacio queer.

Debido a la particularidad de la forma en que los jugadores hablaban y competían, los participantes practicaban y performaban su propia estética. Que esta forma de hablar y jugar indexaba lo queer quedaba claro en la forma como los espectadores percibían el juego. El siguiente extracto corresponde a una entrevista realizada durante un juego de vóley callejero:

J: ¿Tú también juegas?

S: Sí. También juego, pero no, no participo con ellos. Juego solamente vóley femenino.

J: ¿Así callejero o en un equipo?

$S$ : En una liga.

$\mathrm{J}:$ ¿Y juegan bien acá?

S: Sí, algunos, porque él juega liga también, el numero 15, juega en la liga de Perú.

J: ¡Asu!

S: Sí, él también juega vóley masculino.

La espectadora no estaba tan impresionada por la habilidad de los jugadores como yo, pero probablemente esto se debía a que ella estaba más acostumbrada a los partidos. Sin embargo, en la conversación, esta espectadora se explayó sobre la distinción tipológica entre vóley femenino y vóley masculino, los cuales, desde su perspectiva, eran ambos diferentes al tipo de vóley que estábamos mirando. Otro jugador, por ejemplo, juega vóley masculino, o vóley de hombres, pero él no estaba jugando ese tipo de vóley en ese momento en el parque. Después de todo, decía ella, él «también» juega vóley masculino, lo implicaba que su actividad en curso era distinta. Dentro del espacio de la cancha de vóley, los jugadores performaban visiblemente su identidad gay y los espectadores lo reconocían, incluso cuando ser homosexual era tácito y no era un marcador explicitado en ningún momento del juego (Decena, 2011).

Dentro de la cancha de vóley no estaba solo el juego: la cancha también era una arena donde se negociaba, ordenaba y articulaba una estética queer del vóley. Los insultos, los cuales iban y venían entre los jugadores tan a menudo como el juego mismo, eran una práctica a través de la cual los jugadores negociaban la aceptabilidad de su transformación de la calle y de su estatus social estigmatizado. El carácter 
eminentemente lúdico de la actividad enmarcaba el espacio social, de tal manera que el lenguaje y la estética encarnada de los jugadores, normalmente escondida, se volvía visible. Del mismo modo que los jugadores contestaban regulaciones típicas del cuerpo en el vóley, también desafiaron nociones típicas del cuerpo atlético y del espacio en el cual todo ello adquiría significado.

Los juegos de vóley callejero ofrecían una visible $-\mathrm{y}$ no obstante efímeramanifestación de las experiencias de los peruanos gais, así como de sus formas creativas de jugar con el género. En cierto modo, tomar la calle podría estar asociado con privilegios masculinos. La estructura general de los juegos de vóley callejero parecía prestar de cierto modo elementos de la práctica de las pichangas de fútbol. En este último caso, los jugadores normalmente se reunían luego de una pichanga para consumir alcohol y pasar el rato. Esto era también practicado por los jugadores de vóley callejero. Especialmente en los sectores populares de la ciudad donde mi trabajo de campo se realizó, mínimas cantidades de capital económico y simbólico facilitaban formas particulares de masculinidad. El espacio atlético, ya fuese fútbol o vóley, era una arena disponible para la afirmación masculina. Tanto la cancha de fútbol como la de vóley estaban insertas en el espacio público, en contraposición al espacio doméstico marcado como femenino (Fuller, 2001). El control de este espacio podía conseguirse a través de la dominación del deporte en cuestión.

Por otro lado, sin embargo, el vóley estaba íntimamente asociado a la femineidad. El equipo nacional de vóley femenino en el Perú era una fuente importante de orgullo nacional y los juegos y torneos de la selección eran frecuentemente televisados. La derrota del equipo nacional de vóley femenino en la final de la Olimpiadas de 1988 era un evento recordado por muchos. Muy conscientes de esta asociación popular, los jugadores no solo se apropiaban de aspectos femeninos del vóley, sino que también los reconfiguraban en formas significativas y creativas. Muchas mujeres cisgénero también jugaban vóley en la calle, pero sus juegos lucían diferentes de lo que ha sido descrito en este artículo. Por ejemplo, durante el tiempo de mi estudio, no pude observar en este tipo de partidos las prácticas de apostar, insultar o convocar un gran número de espectadores que sí existían en el vóley callejero. Tampoco lo era la emulación constante de aquello que los jugadores consideraban lo opuesto de lo considerado como masculino. Como un informante me explicó, los jugadores se insultaban mutuamente porque el vóley, a diferencia del fútbol, es un deporte sin contacto. Mientras que en deportes como el fútbol los jugadores se golpean mutuamente para desmoralizar al oponente, en el vóley los jugadores debían usar palabras. La agresión era de este modo aún explicita y masculina, pero puesta en práctica de forma diferente, dada la naturaleza particular del vóley. El juego de vóley era una reconfiguración de las asociaciones de género y, más en general, contribuía al desarrollo de una estética deportiva queer. 
En su descripción de las prácticas asociadas al insulto sexual entre los hijra de India, Hall (1997) concluía que los hijras «son capaces de compensar por su propia falta de prestigio social asumiendo control lingüístico de la interacción inmediata, creando espacios sociosexuales alternativos en una geografía de género dicotómicamente organizada» (p. 452). Del mismo modo, los jugadores de vóley también creaban un espacio alternativo en los sectores populares. La interpretación coloquial del vóley callejero como meramente escandaloso y carente de habilidades pierde de vista elementos clave del deporte. Los jugadores transformaban una calle aparentemente incompatible con su modo de vida en una arena para una práctica particular de juego atlético. Sin embargo, la transformación del espacio físico no era efectiva sin la afirmación de control sobre el campo lingüístico. Al insultar y cuestionar las reglas gramaticales de género, los jugadores asumían control del modo en que el lenguaje era usado en el espacio. Esto hacía posible que se abriera un efímero ámbito de posibilidades, en el que la práctica queer florecía. Las prácticas verbales particulares y las performances encarnadas descritas eran posibles en este marco. Si bien estas prácticas también podían tener lugar en otros contextos, estas lo eran mayormente de formas secretas, discretas o estigmatizadas. Por ejemplo, mi informante, que jugaba vóley profesional, podía susurrar un insulto juguetón a un compañero de equipo durante un juego formal, pero esto hubiera constituido una práctica subversiva.

\section{REFERENCIAS}

Alcalde, M. C. (2018). Peruvian lives across borders: Power, exclusión, and home. Urbana, IL: University of Illinois Press. https://doi.org/10.5622/ illinois/9780252041846.001.0001

Bucholtz, M. y Hall, K. (2004). Theorizing identity in language and sexuality research. Language in Society, 33, 469-515. https://doi.org/10.1017/S0047404504334020

Chauvin, L. (2005). Interview with a gay activist: Enrique Bossio. En O. Starn, C. I. Degregori y R. Kirk (eds.), The Peru reader (pp. 502-506). Durham y London: Duke University Press. https://doi.org/10.1215/9780822387503-078

Cornejo, G. (2019). Travesti dreams outside in the ethnographic machine. GLQ: A Journal of Lesbian and Gay Studies, 25, 457-482. https://doi.org/10.1215/10642684-7551140

Cornejo Salinas, G., Martínez, J. y Vidal-Ortiz, S. (2018). LGBT studies without LGBT studies: Mapping Alternative Pathways in Perú and Colombia. Journal of Homosexuality, https://doi.org/10.1080/00918369.2018.1534411

Decena, C. U. (2011). Tacit subjects: Belonging and same-sex desire among Dominican immigrant men. Durham y Londres: Duke University Press. https://doi. org/10.1515/9780822393900 
Fuller, N. (2001). Masculinidades. Cambios y permanencias: varones de Cuzco, Iquitos y Lima. Lima: Pontificia Universidad Católica del Perú.

Geertz, C. (1973). The interpretation of cultures. Nueva York: Basic Books.

Halberstam, J. (2005). In a queer time and place: Transgender bodies, subcultural lives. Nueva York y Londres: New York University Press.

Hall, K. (1997). «Go suck your husband's sugarcane!»: Hijras and the use of sexual insult. En A. Livia y K. Hall (eds.), Queerly phrased: Language, gender, and sexuality (pp. 430460). Nueva York: Oxford University Press.

Hymes, D. (1972). On communicative competence. En J. B. Pride y J. Holmes (eds.), Sociolinguistics (pp. 269-293). Harmondsworth: Penguin.

Murray, S. (1979). The art of gay insulting. Anthropological Linguistics, 21, 211-223.

Parker, R. (1999). Beneath the equator: Cultures of desire, male homosexuality, and emerging gay communities in Brazil. Nueva York: Routledge.

Peña, S. (2004). Pájaration and transculturation: Language and meaning in Miami’s Cuban American gay worlds. En W. L. Leap y T. Boellstroff (eds.), Speaking in Queer Tongues: Globalization and gay language (pp. 230-250). Urbana, IL: University of Illinois Press.

Radcliffe-Brown, A. R. (1977). On joking relationships. En A. Kuper (ed.), The social anthropology of Radcliffe-Brown (pp. 174-186). Londres: Routledge.

Vásquez del Águila, E. (2013). Being a man in a transational world: The masculinity and sexuality of migration. Londres: Routledge. https://doi.org/10.4324/9781315886565 